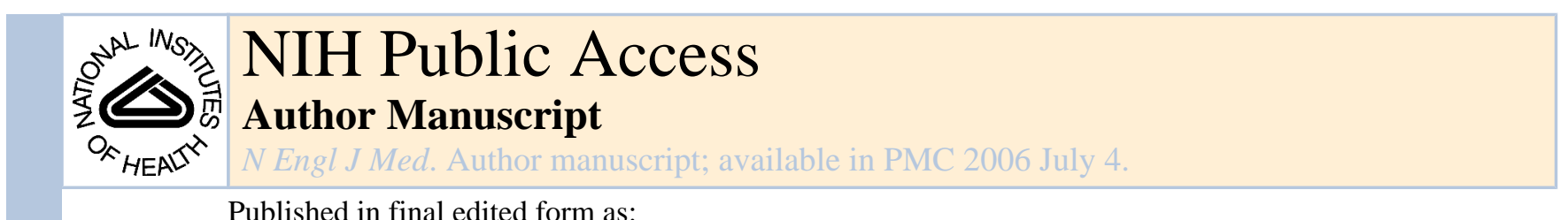

Published in final edited form as:

N Engl J Med. 2005 October 27; 353(17): 1848-1850.

\title{
Developmental Origins of Health and Disease
}

\author{
Matthew W. Gillman, M.D. \\ From the Department of Ambulatory Care and Prevention, Harvard Medical School and Harvard \\ Pilgrim Health Care, and the Department of Nutrition, Harvard School of Public Health - all in \\ Boston.
}

At first glance, it may seem implausible that your mother's exposure to stress or toxins while she was pregnant with you, how she fed you when you were an infant, or how fast you grew during childhood can determine your risk for chronic disease as an adult. Mounting evidence, however, indicates that events occurring in the earliest stages of human development - even before birth - may influence the occurrence of diabetes, cardiovascular disease, asthma, cancers, osteoporosis, and neuropsychiatric disorders.

More than 40 years ago, Widdowson and $\mathrm{McCance}^{1}$ discovered that rat pups that were undernourished during the three weeks of lactation gained weight more slowly over their lifetime than control pups did, even though they had access to ad libitum diets after weaning. In contrast, an identical duration of an energy deficit between 9 and 12 weeks of age had only a short-term effect on weight gain. These experiments showed not only that an environmental insult in early life could have long-term, irreversible consequences, but also that the insult must occur during a critical period in development to have maximal effect.

In the years since, investigators have induced such developmental programming of adverse health outcomes in many animal species with the use of diverse interventions, ranging from the modification of the maternal (or even the grandmaternal) diet to the prenatal administration of glucocorticoid hormones, ligation of the uterine artery, experimentally produced anemia, and alteration of postnatal growth. ${ }^{2}$ These perturbations can result in the adverse development of organs or organ systems directly or in adaptive responses that may be beneficial in the short term but deleterious in the long run. Because such experiments in animals involve environmental changes, they do not address purely genetic influences, but epigenetic processes may play a key role in the mechanisms underlying these phenomena. ${ }^{2}$

Although experiments in animals illustrate the principle that adult health outcomes can trace some of their roots to early development, the extent to which similar developmental processes explain variations in human health outcomes remains unclear. The first generation of epidemiologic studies found intriguing associations between birth weight and disease outcomes decades later. ${ }^{3}$ Researchers have found consistent inverse associations between birth weight and a central distribution of body fat, insulin resistance, the metabolic syndrome, type 2 diabetes mellitus, and ischemic cardiovascular disease. ${ }^{4}$ Moreover, the phenotype of lower birth weight coupled with a higher body-mass index in childhood or adulthood appears to be associated with the highest risks of these outcomes. This pattern holds, for example, for insulin resistance in children eight years of age in India, ${ }^{5}$ blood pressure among Filipino adolescents, 6 the metabolic syndrome among white and Mexican-American adults, ${ }^{7}$ and coronary heart disease among Welsh men and among American women who are nurses. 8,9

Supported by a grant from the National Institutes of Health (HL 068041).

Dr. Gillman reports having received grant support from Sanofi Aventis and Mead Johnson Nutritionals. 
In this issue of the Journal, Barker and colleagues, ${ }^{10}$ taking advantage of unusually extensive data from Finland on childhood growth and adult outcomes, present a detailed analysis of this pattern. As compared with members of the cohort in whom heart disease outcomes did not develop, those who were hospitalized for or died from coronary heart disease had relatively small body size during the first two years of life, then grew more rapidly through 11 years of age. This growth pattern also predicted elevations in biomarkers for insulin resistance, which is a risk factor for coronary disease. Adjusting for variables that represent social and economic circumstances in adulthood did not appreciably change the results. Although some differences appeared to be present between the affected boys and girls in patterns of growth during infancy, the limited number of cardiac events among women precludes strong inferences.

Together with published results from India showing that an increasing body-mass index through adolescence confers an excess risk of impaired glucose tolerance in early adulthood, 11 the findings of Barker et al. provide evidence that for those with a relatively low birth weight, excess weight gain during childhood and adolescence portends a particularly poor prognosis for the development of coronary heart disease in adulthood.

One issue that remains unresolved is the role of early postnatal growth from birth to two years of age. In contrast to the findings of Barker et al., recent observational studies of full-term infants and randomized trials involving premature infants suggest that accelerated weight gain during infancy, even during the first weeks of life, can result in overweight, insulin resistance, and high leptin levels and blood-pressure levels one to two decades later. ${ }^{12,13}$ Some of the discrepancies between the studies may have resulted from the limitations of body-mass index to represent true fatness, variable loss to follow-up, and differences in infant growth from one era to another. Furthermore, published intervention trials are restricted to premature infants. Getting the right answers, however, is more than an academic issue. If rapid weight gain in infancy is indeed harmful to adult health, then clinicians and public health professionals are faced with many challenges, including those of overcoming cultural stereotypes suggesting that "a big baby is a healthy baby," considering whether growth charts based largely on formula-fed infants are still appropriate, questioning whether to continue using energyenriched formulas for premature infants, and devising more effective strategies to promote the duration and exclusivity of breast-feeding.

Beyond reproducing the observation that lower birth weight is associated with heart-disease outcomes, Barker et al. do not address the area of research most readers will associate with Professor Barker's name - the prenatal origins of adult disease. Birth weight is easily measured and is available from historical records, but if the truth be told, it is a dreadful marker of prenatal etiologic pathways. ${ }^{14}$ Fortunately, a new generation of epidemiologic studies directly examine the effects of prenatal determinants on postnatal health outcomes, irrespective of birth weight. Investigators have recognized that the initially invoked concept of maternal undernutrition is a simplistic model of prenatal influences. They now consider perturbations anywhere along the entire fetal-supply line, which includes not only maternal diet but also uteroplacental blood flow, placental function, and fetal metabolism.

Recent studies of maternal diet during pregnancy indicate, for example, that the higher a mother's intake of fish, if the fish is low in mercury content, the higher the child's score will be on a test of cognition, 15 and the higher the mother's calcium intake, the lower the child's blood-pressure level will be. ${ }^{16}$ Despite the known relationship between smoking and reduced fetal growth, maternal smoking during pregnancy is associated with an increased risk of obesity in the offspring. ${ }^{17}$ Experiments in animals show that reduced activity of the placental enzyme $11 \beta$-hydroxysteroid dehydrogenase type 2 programs hypertension and hyperglycemia in the offspring, as a result of excess fetal exposure to glucocorticoids. ${ }^{18}$ Gestational diabetes (which is associated with higher birth weight) leads to fetal hyperinsulinemia and is associated with 
obesity and impaired glucose tolerance in the growing child. ${ }^{19}$ The treatment of gestational diabetes is effective in reducing adverse perinatal outcomes, ${ }^{20}$ but its long-term effectiveness in reducing obesity-related consequences in the offspring is not known, and evidence with regard to strategies to prevent gestational diabetes is scarce. Indeed, for most of the epidemiologic associations described to date, the extent to which interventions that are intended to modify risk can improve long-term health is not yet clear.

In populations of the world that are undergoing the nutritional and epidemiologic transition to Western styles of diet, sedentary behavior, obesity, and chronic diseases, the ominous pattern that Barker et al. identify - lower birth weight followed by excess weight gain in childhood — is both common and liable to persist for the foreseeable future. It is therefore imperative that, along with vigorous efforts to optimize childhood growth, researchers and policymakers identify, quantify, and evaluate strategies to modify prenatal and perinatal determinants of adverse adult health outcomes. These are the goals of the field of inquiry known as the developmental origins of health and disease, which is now represented by a learned society, the International Society for Developmental Origins of Health and Disease, and by yearly interdisciplinary congresses that are devoted to catalyzing a rapid expansion of research and policy initiatives. Slowly but surely, investigators in this field are learning ways by which ensuring the well-being of women of reproductive age and their newborn children can have substantial health-promoting effects in the next generation.

\section{References}

1. Widdowson EM, McCance RA. The effect of finite periods of undernutrition at different ages on the composition and subsequent development of the rat. Proc R Soc Lond B Biol Sci 1963;158:329-42. [PubMed: 14070049]

2. McMillen IC, Robinson JS. Developmental origins of the metabolic syndrome: prediction, plasticity, and programming. Physiol Rev 2005;85:571-633. [PubMed: 15788706]

3. Barker DJP. Mothers, babies, and disease in later life. 2nd ed. New York: Churchill Livingstone, 1998.

4. Oken E, Gillman MW. Fetal origins of obesity. Obes Res 2003;11:496-506. [PubMed: 12690076]

5. Bavdekar A, Yajnik CS, Fall CHD, et al. Insulin resistance syndrome in 8-year-old Indian children: small at birth, big at 8 years, or both? Diabetes 1999;48:2422-9. [PubMed: 10580432]

6. Adair LS, Cole TJ. Rapid child growth raises blood pressure in adolescent boys who were thin at birth. Hypertension 2003;41:451-6. [PubMed: 12623942]

7. Valdez R, Athens MA, Thompson GH, Bradshaw BS, Stern MP. Birthweight and adult health outcomes in a biethnic population in the USA. Diabetologia 1994;37:624-31. [PubMed: 7926349]

8. Frankel S, Elwood P, Sweetnam P, Yarnell J, Smith GD. Birth-weight, body-mass index in middle age, and incident coronary heart disease. Lancet 1996;348:1478-80. [PubMed: 8942776]

9. Rich-Edwards JW, Kleinman K, Michels KB, et al. Longitudinal study of birth weight and adult body mass index in predicting risk of coronary heart disease and stroke in women. BMJ 2005;330:1115. [PubMed: 15857857]

10. Barker DJP, Osmond C, Forsén TJ, Kajantie E, Eriksson JG. Trajectories of growth among children who have coronary events as adults. N Engl J Med 2005;353:1802-9. [PubMed: 16251536]

11. Bhargava SK, Sachdev HS, Fall CH, et al. Relation of serial changes in childhood body-mass index to impaired glucose tolerance in young adulthood. N Engl J Med 2004;350:865-75. [PubMed: 14985484]

12. Stettler N, Stallings VA, Troxel AB, et al. Weight gain in the first week of life and overweight in adulthood: a cohort study of European American subjects fed infant formula. Circulation 2005;111:1897-903. [PubMed: 15837942]

13. Singhal A, Lucas A. Early origins of cardiovascular disease: is there a unifying hypothesis? Lancet 2004;363:1642-5. [PubMed: 15145640]

14. Gillman MW. Epidemiological challenges in studying the fetal origins of adult chronic disease. Int J Epidemiol 2002;31:294-9. [PubMed: 11980782] 
15. Oken E, Wright RO, Kleinman K, et al. Maternal fish consumption, hair mercury, and infant cognition in a U.S. cohort. Environ Health Perspect 2005;113:1376-80. [PubMed: 16203250]

16. Gillman MW, Rifas-Shiman SL, Kleinman KP, Rich-Edwards JW, Lipshultz SE. Maternal calcium intake and offspring blood pressure. Circulation 2004;110:1990-5. [PubMed: 15451777]

17. Toschke AM, Montgomery SM, Pfeiffer U, von Kries R. Early intrauterine exposure to tobaccoinhaled products and obesity. Am J Epidemiol 2003;158:1068-74. [PubMed: 14630602]

18. Seckl JR. Glucocorticoid programming of the fetus: adult phenotypes and molecular mechanisms. Mol Cell Endocrinol 2001;185:61-71. [PubMed: 11738795]

19. Gillman MW, Rifas-Shiman SL, Berkey CS, Field AE, Colditz GA. Maternal gestational diabetes, birth weight, and adolescent obesity. Pediatrics 2003;111:e221-e226. [PubMed: 12612275]

20. Crowther CA, Hiller JE, Moss JR, McPhee AJ, Jeffries WS, Robinson JS. Effect of treatment of gestational diabetes mellitus on pregnancy outcomes. N Engl J Med 2005;352:2477-86. [PubMed: 15951574] 